\title{
Impact of COVID-19 Lockdown on the Readiness of Preschool Educators for Distance Learning
}

\author{
Pavlenko G.V. ${ }^{1, *}$ PavlenkoA.I. ${ }^{2}$ \\ ${ }^{1}$ Far Eastern Federal University, a branch of FEFU in Ussuriysk, Ussuriysk, Russia \\ ${ }^{2}$ Primorsky State Agricultural Academy, Ussuriysk, Russia \\ *Corresponding author. Email: gpavlenko_62@mail.ru
}

\begin{abstract}
In Russia, in March-April 2020, as part of the COVID-19 lockdown, almost all preschool educational institutions were closed, but the e-learning format was much less in demand than in other countries.

From the one hand this situation can be explained as Russian preschool institutions interpret the distance format as possible (for example, for certain categories of children), but not mandatory. Therefore, in Russia preschool teaching during the lockdown period can be characterized as spontaneous in using of distance learning technologies, which is explained, among other things, by the unpreparedness of preschool institutions for such work. Important factors of such readiness: the level of digital literacy of educators; the level of technical (digital) equipment (tools) of preschool institutions; active interest in distance technologies on the part of teachers and parents. The authors suggested that, even in a situation of rare use of distance technologies during the lockdown period, the public demand for such work was reported to contribute to create a positive attitude towards distance learning among preschool teachers. This article is devoted to testing this assumption.
\end{abstract}

Keywords: COVID-19 lockdown, preschool education, digital technology, distance learning, preschool

teachers

\section{INTRODUCTION}

The COVID-19 lockdown most voiced manifestation in education was the massive use of distance learning technologies from March to June of 2020. According to UNESCO data for June 2020, about $75 \%$ of students in all countries of the world switched to distance learning. The compulsion of this transition, the need to organize it in the shortest possible time and at the same time ensure the proper quality of educational services, caused an ambiguous attitude to distance learning on the part of all participants in the educational process.

People take this situation in a such dramatic way because of the scale of it, since the distance learning format itself has long been one of the usual options for the educational process [1]. In publications on the impact of the COVID-19 pandemic on education, it is noted that, for almost all countries of the world, the main problem has become the need for online education engagement in a huge broad way, which is mandatory for all educational institutions, which otherwise would simply have to be closed [2,3]. Therefore, the interest of researchers today is focused mainly on finding out which countries, and due to what, managed to most effectively switch to the massive use of distance learning technologies [4,5].

In Russia, in March-April 2020, as part of the COVID-19 lockdown, almost all preschool educational institutions were closed, but the e-learning format was much less in demand than in other countries [6,7]. From the one hand this situation can be explained as Russian preschool institutions interpret the distance format as possible (for example, for certain categories of children), but not mandatory $[8,9]$. In additional, until recently the main emphasis in methodological work was made on Information and Communication technologies (ICT) use recommendations directly in kindergartens $[10,11]$.

Therefore, in Russia preschool teaching during the lockdown period can be characterized as sporadic in using of distance learning technologies, which is explained, among other things, by the unpreparedness of preschool institutions for such work $[8,12]$. Important factors of such readiness: the level of digital literacy of educators; the level of technical (digital) equipment (tools) of preschool institutions; active interest in distance technologies on the part of teachers and parents $[13,14,15]$. The authors suggested that, even in a situation of rare use of distance technologies during the lockdown period [16], the public demand for such work was reported to contribute to create a positive attitude towards distance learning among preschool teachers. This article is devoted to testing this assumption.

\section{RESEARCH METHODOLOGY}

The study was prepared with automatic anonymous online survey using a questionnaire posted in a Google Forms and comparing the results obtained in the course of our study with similar local and foreign ones. 
Research objective: source information collection to determine the preschool teachers' attitude to the use of distance learning technologies during the COVID-19 lockdown.

Research methods:

- preschool teachers' attitude screening of the distance learning technologies use when working with preschoolers during the lockdown;

- the results obtained comparison with the results of similar studies

Respondents sampling: educators and senior educators of preschool educational institutions

Research problems:

1. Necessary information collection through interview (questionnaire) of educators.

2. Establishing the relationship between the level of digital tools proficiency among preschool teachers and their age and work experience.

3. Revealing how the preschool educational institutions are equipped with digital tools and in what level of proficiency do the preschool institutions teachers use them.

4. Making the description of the attitude of preschool teachers towards the use of distance technologies in the practice of working with preschool children during the lockdown.

5. Determination of the readiness of teachers and parents to use distance technologies in the practice of working with preschool children during the second wave of the lockdown. Research indicators: The questionnaire included 16 questions, which we divided into three blocks in accordance with the objectives of our study. Each block contains two parameters:

Block 1. Assessment of how the preschool educational institutions are equipped with digital tools and in what level of proficiency do the preschool institutions teachers use them:

- availability and diversity of digital equipment (tools) in preschool educational institutions;

- self-assessment of the level of proficiency in using the digital equipment by teachers of preschool institutions.

Block 2. The description of the attitude of preschool institutions teachers and parents to the use of distance technologies during the lockdown:

- the presence or absence of a positive attitude towards the use of distance technologies;

- experience in arranging of remote interaction of preschool teachers with parents and children during the lockdown.

Block 3. Assessment of the readiness of teachers and parents to use distance technologies in the practice of working with preschool children:

- self-assessment of the readiness of teachers to use distance learning technologies (level of digital literacy, experience in using distance technologies, understanding the importance of remote work with children during the period of self-isolation);

- teachers' assessment of the technical capabilities and readiness of parents for remote work during the second wave of the COVID-19 lockdown.

\section{RESEARCH FINDINGS}

192 educators and senior educators of preschool educational institutions of Primorskiy krai took part in an anonymous online interview. The survey was conducted in October 2020 , i.e. 2-3 months after the end of the period of selfisolation and the beginning of the work of preschool institutions.

The questionnaire suggested: description of the availability and options for using digital equipment in preschool establishments; clarification of the attitude of educators to remote work with children that developed during the lockdown period; assessment of the readiness of educators and parents for distance learning in the context of a possible second wave of the COVID-19 pandemic.

The first questions of the questionnaire were aimed at identifying the relationship between the level of digital equipment proficiency among preschool teachers, their age and work experience.

Educators were asked about age and seniority in preschool education. Most of the respondents $-44.3 \%$, who took part in the survey, belong to the age group from 36 to 50 years old; $32.3 \%$ - over 50 years old; $23.4 \%$ - from 20 to 35 years old. At the same time, $30.2 \%$ work in educational institutions of preschool education from 6 to 15 years; $26.6 \%$ - over 26 years; $21.9 \%$ and $21.4 \%$ - respectively from 16 to 25 and less than 5 years.

To assess how preschool educational organizations are equipped with digital tools, the question was asked about the availability of digital equipment for conducting classes in the kindergarten group: $80.7 \%$ of respondents indicated that they have multimedia equipment; $16.1 \%$ of educators have an interactive whiteboard; $8.3 \%$ answered that they have tablets for working with children; $0.5 \%$ of educators have multimedia studios for children and interactive tables. Regarding the use of digital equipment in their work $56.8 \%$ of educators answered that they use digital equipment sometimes; $31.8 \%$ of educators regularly use; $11.5 \%$ never use digital equipment when working with children.

On the possibility of access of children of a group at kindergarten to digital equipment: the majority of teachers $(86 \%)$ answered that children do not have such access, but $14 \%$ of teachers allow children to use digital equipment with varying degrees of regularity.

So, when asked about the frequency of communication with parents, friends, colleagues through social media, $78.6 \%$ of educators indicated that a group has been created in social media through which communication with parents occurs; $17.7 \%$ noted that they sometimes communicate with their parents; $3.6 \%$ - maintain relationships with parents, colleagues and friends through social media. When asked, "Did you keep in touch with parents and children during the period of self-isolation?" The majority of teachers, $54.2 \%$, noted that they communicated through a group on social media; $38.5 \%$ corresponded occasionally; $7.3 \%$ indicated that there was no communication.

The question about the possible purpose of such communication had the following wording: "Did you provide professional psychological and pedagogical support to parents and children during the period of self-isolation?" 
The answers were distributed as follows: $57.3 \%$ of educators indicated that they contacted individual parents several times during the period of self-isolation; $29.2 \%$ systematically got in touch with parents, were interested in what the children were doing at home and gave recommendations to parents; $13.5 \%$ - did not maintain contact with parents during the lockdown period.

To find out the degree of communication between educators and the family, a question was asked about the presence of a request from parents to organize distance classes with children: $66.1 \%$ of teachers noted that parents did not show interest in remote work with children; $26.6 \%$ indicated that parents expressed difficulties in organizing children's activities; $7.3 \%$ noted that parents were often interested in the possibility of remote classes.

When asked, "Do you think that during the period of selfisolation during the second wave of COVID-19, it is necessary for a kindergarten to work remotely with children?" $48.7 \%$ of educators noted that remote work during the period of self-isolation should be carried out only at the request of parents; $31.3 \%$ indicated that teleworking with children during the period of self-isolation is optional; $22.9 \%$ answered that in conditions of self-isolation, a kindergarten should continue to work with children in a remote format.

The questionnaire also included questions about whether educators have the competencies necessary for the remote format.

So, to the question "Have you studied at advanced training courses in the use of digital equipment and digital technologies?", $31.8 \%$ of educators indicated that they were trained; $19.8 \%$ answered that they participated in a shortterm training (seminar or webinar); $44.8 \%$ admitted that they did not go through such studies.

Regarding the need for additional training (refresher courses) for remote work with children: $63 \%$ of the respondents answered that additional training is needed, they would like to know about the possibilities of various platforms for the implementation of distance learning, as well as the forms and methods of remote work with children; $11.5 \%$ believe that they are already ready to carry out remote work with children; $25.5 \%$ said that they do not need additional training, since they do not plan to study with children remotely.

When asked what classes with children do educators use such equipment, the majority, $71.4 \%$, answered that they use digital equipment to familiarize children with the world around them; $16.7 \%$ - for work on the development of speech; $7.3 \%$ - for lessons in drawing, modeling, application; $3.1 \%$ - for classes in mathematics; $1.6 \%$ - for construction classes. At the same time, $32.3 \%$ of teachers believe that they are confident users of digital tools; $57.8 \%$ admitted that they sometimes have difficulties in using digital tools; $9.9 \%$ indicated that they constantly experience difficulties.

One of the important components of the research was to find out the opinion of teachers about the readiness of parents to work remotely with children. To the question, "Did parents asked you advises on how to engage their children with some activities during the period of self-isolation?" the teachers' answers were divided into three groups: $41.7 \%$ indicated that parents did not seek advice from kindergarten teachers; $41.1 \%$ answered that they have been asking several times during the period of self-isolation; $17.2 \%$ reported that parents often asked for advice on what to do with their children during the period of self-isolation.

When asked about the desire of parents for the kindergarten to conduct distance work with children, $50 \%$ of teachers answered that parents do not want distance learning; $21.9 \%$ - that parents express a desire to conduct remote work with their children, but the family does not have relevant technical digital tools; according to $21.4 \%$ of educators, parents are not ready to work remotely with children; $6.8 \%$ of educators indicated that parents are ready for the remote format and most of them have the necessary technical capabilities.

\section{DISCUSSION}

It turned out that teachers of all age groups use digital technologies and digital equipment in their practice with varying degrees of regularity, their level of digital equipment does not correlate with experience and age.

Perhaps it can be explained because during the lockdown, many teachers were included in various forms of distance learning (refresher courses, seminars and webinars), which ensured the acquisition of experience in using digital equipment. According to our data, more than $50 \%$ of the total number of preschool education teachers in the Primorskiy krai took part in educational programs involving the use of distance technologies. In addition, during the lockdown, almost three quarters of Primorskiy krai educators communicated with parents and colleagues through social networks or various remote platforms, which also allowed them to gain relevant experience.

Older educators, we assume, constitute the majority of the $20 \%$ who do not use, or rarely use digital equipment in their work. Also, the older age group includes mainly those $50 \%$ who do not have additional education in the field of digital equipment and digital technologies.

Since the majority of all workers in preschool institutions in the Primorskiy krai is older age people, it is not surprising that even the digital equipment available in these institutions is not being used effectively enough. Children are virtually deprived of access to it, and $85 \%$ of the teachers surveyed confirmed that they do not allow children to work with digital equipment, never allow children to use digital equipment in the classroom and in independent activities.

But, as recent studies of the practice of introducing ICT in preschool institutions in Turkey, Croatia and Greece show, it is not only a lack of digital literacy $[17,18,19]$. From the didactic point of view, the equipment, which is mostly available in kindergartens, is supposed to be used only as a visual means for demonstrating illustrations, paintings, as well as images of characters in didactic games and assignments. By means of multimedia presentations, it is possible to introduce a child into a problematic situation, thereby stimulating the manifestation of cognitive and other 
types of activity, but to conduct full-fledged classes that allow children to be active (to act as a subject of joint activities with a teacher and children), more complex equipment is needed (tablets, multimedia studios, interactive whiteboards), which is available only in some kindergartens of the Primorskiy krai.

Teachers" answers to the questions about whether they maintained relations with parents and children during the period of self-isolation through social networks, whether they provided professional psychological and pedagogical support to parents and children during the period of selfisolation, whether they consider it important to carry out remote work with children during the period of selfisolation, and others allowed to reveal the attitude of teachers to remote work with children. Almost $80 \%$ of teachers maintained relationships with parents, communicated with them about the upbringing and education of children, gave advice on how to keep the child busy. In many kindergarten groups, teachers have established a connection with their parents through social networks.

However, not all teachers contact parents through social media, they are interested in direct communication, and since such communication turned out to be impossible, these teachers practically did not communicate with parents and children during the period of self-isolation. It is typical that during the lockdown period, only $30 \%$ of teachers were systematically interested in what the children were doing at home and gave recommendations to parents. Many teachers only contacted individual parents a few times and only at their request, which indicates a lack of interest in the kindergarten in what the children are doing at home and what difficulties parents and children have.

These results correlate positively with the data we obtained from our earlier research of parents on their relationship with the kindergarten during the lockdown period. At that time, the majority of parents, at least $70 \%$ of the total number of respondents, reported that they did not need contacts with kindergarten workers, and $33 \%$ of parents turned to kindergarten employees with varying degrees of intensity from "sometimes" to "often"[20].

The lack of mutual interest of the kindergarten employees and the family in constant contact is confirmed by the fact that only $22.5 \%$ believe that during the period of selfisolation it is necessary to continue working with children in a remote format. The overwhelming majority, $77.5 \%$, consider such work unnecessary or possible, at best, exclusively at the request of the parents. In our opinion, such an attitude of teachers to the distance format may be due not only to the lack of relevant experience, but also to underestimation of the parents' ability to provide the necessary technical means [8], but to the presence of a certain prejudice against remote forms of work in the upbringing and teaching of preschool children.

The validity of this assumption is also confirmed by the conclusions made in 2019 by the authors of the study "The Obstacles to ICT Implementation in the Kindergarten Environment: Kindergarten Teachers' Beliefs". Based on the research, the main types of obstacles in their beliefs were identified that hinder the effective implementation of
ICT in preschool education: "(1) pedagogically, despite acknowledgment of its value, ICT does not play a key role in the kindergarten teachers' education philosophy; (2) didactically, ICT is used mainly as a source of information and for instructional illustration, rather than as a means to new teaching strategies " [21].

The results of our questionnaire showed the insufficient readiness of teachers and parents to use remote technologies in the practice of working with preschool children during the period of a possible second wave of the COVID-19 lockdown. Why was their readiness not stimulated by the experience of the first wave of lockdown? The reason, perhaps, is the poor remote activities engagement of preschool institutions under conditions of quarantine and self-isolation in April-May 2020.This assumption is confirmed by a recent study of the effect of lockdown on preschool education in Russia, the authors of which stated that due to the pandemic, "preschool educational institutions found themselves in a situation of uncertainty, and the process of distance learning took place mainly spontaneously, poorly controlled by the administration and by the teaching staff's concerns" [12].

At the same time, the teachers we interviewed give a rather high assessment of their own level of digital literacy, identifying themselves as "competent users". This, apparently, was facilitated by the massive participation of educators in various advanced training programs in the use of digital equipment and digital technologies, aimed to obtain basic competencies for the use of distance technologies. These competencies among the educators we interviewed are in demand, first of all, in engaging classes of introducing children of their group with the world around them, in the format of making presentations.

However, this kind of experience seems to be insufficient if we foresee a lockdown to be repeated and large-scale effective use of remote sensing technologies will be still in demand. This conclusion may be verified, for example, on the basis of the American authors lockdown practice of distance learning analysis. Thus, the opinion is expressed about the need for special programs for the training of teachers, in which it would be possible to work out not only technical aspects, but also methodological ones, since distant work requires the involvement of all participants in the educational process of teachers, parents and children [13].

One of the key tasks of engaging of effective distance learning is parents support and involvement. The problem is that, according to the majority of our respondents, parents do not want distance learning for preschoolers and are not ready for it. According to them, the overwhelming majority of families do not have the necessary technical conditions for organizing remote work with children. These data also coincide with the findings by Tarasova N., Pestrikova S., which confirm the low motivation of parents to work with preschool children, but the reason is that the kindergarten staff could not establish proper interaction with parents [12]. 


\section{CONCLUSION}

The study completed was pilot and made it possible to determine how preschool institutions are equipped with digital tools, and also the attitude of teachers to the remote format of coordination and the readiness of teachers and parents to work remotely with children.

Teachers of all age groups and work experience use digital technologies and digital equipment in their practice differently in time. During the lockdown, teachers were involved in various forms of distance learning, communicated with parents and colleagues by Social Media, various remote communication platforms.

Primorskiy krai preschool institutions are generally poorly equipped with digital tools. Kindergartens have digital tools mainly for preparing and demonstrating multimedia presentations. Insufficient number of interactive whiteboards, tablets, multimedia studios, etc. does not allow children to have access to them and thereby contribute to the acquisition of experience in using digital equipment for both adults and children.

Primorskiy krai teachers generally have a negative attitude towards the possibility of mass introduction of remote forms of work with children. This is based, in particular, on their conviction that the majority of parents have no interest in the remote format and that families have not equipped enough with relevant digital tools.

\section{REFERENCES}

[1] V. Singh, A. Thurman, How Many Ways Can We Define Online Learning? A Systematic Literature Review of Definitions of Online Learning (1988-2018), American J. of Distance Education, 33(4) (2019) 289306. DOI: $10.1080 / 08923647.2019 .1663082$

[2] L. Espino-Díaz, G. Fernandez-Caminero, C.-M. Hernandez-Lloret, H. Gonzalez-Gonzalez, J.-L. Alvarez-Castillo, Analyzing the Impact of COVID-19 on Education Professionals, Toward a Paradigm Shift: ICT and Neuroeducation as a Binomial of Action. Sustainability MDPI, Open Access Journal, 12(14) (2020) 1-10. DOI: 10.3390/su12145646

[3] N. Mustafa, Impact of the 2019-20 coronavirus pandemic on education. International Reseacher Conference, 2020. DOI:10.13140/RG.2.2.27946.98245

[4] I. Pramling Samuelsson, J.T. Wagner, E. Eriksen Ødegaard, The Coronavirus Pandemic and Lessons Learned in Preschools in Norway, Sweden and the United States: OMEP Policy Forum. IJEC 52, 2020, pp. 129-144. DOI: 10.1007/s13158-020-00267-3

[5] T. Dreesen, S. Akseer, M. Brossard, P. Dewan, J-P. Giraldo, A. Kamei, S. Mizunoya, O. Correa, J. Santiago, Promising Practices for Equitable Remote
This attitude was formed due to the insufficient level of educators' competencies necessary for remote work with children engagement, a massive lack of experience in this work during the lockdown period, and an underestimation of the family's ability to create conditions for a remote format. Typically, those of the educators who used remote forms of work during the period of self-isolation in the first wave of the COVID-19 pandemic confirm their effectiveness.

Thus, according to the results of the study, it should be stated that COVID-19 lockdown had no pronounced effect to preschool educators' readiness to distance learning. Lockdown did not become an incentive for teachers to revise their professional experience in the sense of realizing the necessity of acquiring the competencies necessary for organizing effective distance learning for preschoolers.

The conclusions drawn refer only to preschool education in Primorskiy krai and cannot be extrapolated to preschool education in Russia as a whole. However, the results obtained indicate the importance of examining the attitude of teachers to the distance format for assessing the prospects of distance learning for preschoolers if lockdown situation will happen again.

Learning. Emerging lessons from COVID-19 education responses in 127 countries, Innocenti Research Briefs no. 2020-10, UNICEF Office of Research Innocenti, Florence, 2020.

[6] A. Dozhdikov, On trends and measures taken in the global education systems in connection with the COVID-19 virus pandemic, educational technologies and digital applications used, Monitoring the economic situation in Russia: trends and challenges of socioeconomic development, 10(112) (2020) 174-180.

[7] N. Tarasova, K. Tarasova, Preschool education and distance learning. International review, Preschool education, 8 (2020) 22-28

[8] A. Vasilyeva, The bell rings for the parent. Every fourth family more often helped the child to study during the period of «distance learning», 2020.

[9] S. Novikova, Functioning of kindergartens during a pandemic: the practice of regions, Monitoring the economic situation in Russia: trends and challenges of socio-economic development, 8(110) (2020) 83-89.

[10] T. Komarova, I. Komarova, A. Tulikov Information and communication technologies in preschool education: a practical guide, Moscow, 2011, $128 \mathrm{p}$. 
[11] N. Fedina, I. Burmykina, L. Zvezda, O. Pikalova, D. Skudnev, I. Voronin, Sociological analysis of the readiness of participants in educational activities to implement distance educational technologies in preschool education, Humanitarian studies of Central Russia, 3(4) (2017) 94-111. DOI: 10.24411/2541-90562017-00032

[12] N. Tarasova, S. Pestrikova, The system of preschool education during a pandemic. Monitoring, Preschool education, 10 (2020) 88-96

[13] J. Kim, Learning and Teaching Online During Covid-19: Experiences of Student Teachers in an Early Childhood Education Practicum, IJEC 52, pp.145-158. (2020). DOI: 10.1007/s13158-020-00272-6

[14] D. Masoumi, Preschool Teachers' use of ICTs : Towards a typology of practice. Contemporary Issues in Early Childhood, 16 (1) (2015) 5-17. DOI:

$10.1177 / 1463949114566753$

[15] S. Kerckaert, R. Vanderlinde \& J. van Braak, The role of ICT in early childhood education: Scale development and research on ICT use and influencing factors. European Early Childhood Education Research Journal, 23(2) (2015) 183-199. DOI:

10.1080/1350293X.2015.1016804

[16] N.Tarasova, S. Pestrikova, «Open MIC» Teachers' opinions on the work of pre-school educational organizations during the pandemic, Preschool education, 11 (2020) 73-76.

[17] A.S. Konca, E. Ozel, H. Zelyurt, Attitudes of preschool teachers towards using information and communication technologies (ICT), Int. J. of Research in Educ. and Science, 2(1) (2016) 10-15.

DOI:10.21890/ijres.21816

[18] N.M. Preradović, G. Gordana Lešin, D. Boras, The role and attitudes of kindergarten educators in ICTsupported early childhood education, Technology, Education, Management, 6(1) (2017) 162-172. DOI: 10.18421/TEM61-24

[19] M. Vitoulisi, The formation of pre-service early childhood educators' perceptions about ICT use in early childhood education after an experiential approach, European J. of Education Studies, 3(5) (2017) 22-37. DOI: $10.46827 /$ ejes.v0i0.621

[20] G. Pavlenko, A. Pavlenko, Digital Literacy as a Condition for Positive Experience of the COVID-19 Lockdown for Families With Preschool Children, Proc. of the Research Technologies of Pandemic Coronavirus
Impact Advances in Social Science, Education and Humanities Research, 486 (2020) 507-512. DOI: 10.2991/assehr.k.201105.090

[21] N. Magen-Nagar, E. Firstater, The Obstacles to ICT Implementation in the Kindergarten Environment: Kindergarten Teachers' Beliefs, Journal of Research in Childhood Education, 33(2) (2019) 165-179.

DOI: $10.1080 / 02568543.2019 .1577769$ 